\title{
Obituaries
}

\section{Gerald Francis Morris Russell, MD, FRCP, FRCPsych, DPM}

Formerly Professor of Psychiatry, Institute of Psychiatry, and Consultant Psychiatrist, Bethlem and Maudsley Hospital, UK.

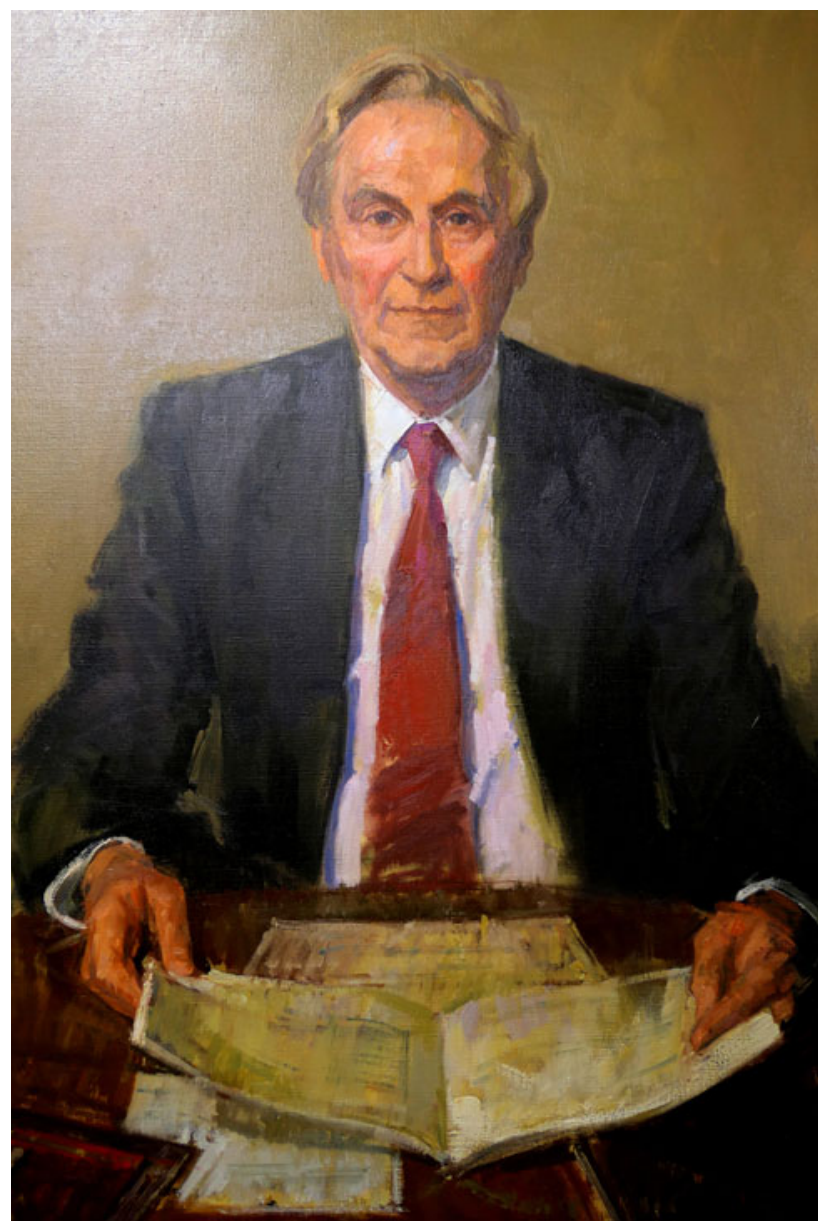

Gerald Russell, who died on 26 July 2018 at the age of 90, was a central figure in the modern history of our understanding of eating disorders. International colleagues often referred to him as the specialty's elder statesman. He was the complete clinician scientist, marrying sharp clinical observation with inventive experimental methods appropriate to the elucidation of significant clinical phenomena. These skills were associated with an unusually deep commitment to his patients and to service (for which he received a British Citizen Award). As dean of the Institute of Psychiatry (1966-1970), as professor of psychiatry at the Royal Free Hospital School of Medicine (19711979) and then - returning to the Institute of Psychiatry - as professor of psychiatry (1979-1993), he was an effective leader, a wise teacher and was exceptionally generous in helping many colleagues - academic and clinical - realise their career aspirations.
Gerald's earliest original contribution was his characterisation in 1970 of the core psychopathology of anorexia nervosa: the intense 'fear of fatness' (so exasperating for the interlocutor) and the associated distorted perception of body image. ${ }^{1}$ His delineation of the illness - a combination of the psychopathology, the weight loss (due to a 'studied and purposive avoidance of foods') and amenorrhoea - was reflected in later ICD and DSM classifications. But acute observation was not enough. How could experimentation elucidate the nature of the body image disturbance? Gerald devised an ingenious calliper set-up where exact measurements could be made of patients' estimations of their body widths at chest, waist and hips. Compared with controls, they grossly overestimated by up to $50 \%$, but this reversed with weight gain.

The identification of the 'ominous variant' of anorexia nervosa, bulimia nervosa, in 1979 was another observational coup and the one most firmly linked to his name. ${ }^{2}$ Bulimia nervosa was promptly added to the diagnostic classifications. Related was a description of probably the only physical sign named after a psychiatrist, 'Russell's sign', which describes the abrasions on the knuckles resulting from using the fingers to induce vomiting. Bulimia nervosa became so commonly diagnosed that Gerald sometimes worried that the attention generated by his description may have somehow contributed to its growing incidence. He was thoroughly conversant with the history of eating disorders, from medieval times to the present, and he noted how pathoplasticity was illustrated in the various forms the disorders adopted at different times.

Gerald also oversaw significant treatment developments at the Maudsley Hospital. The essentials of the particular style of in-patient nursing care of people with anorexia nervosa were clearly set out in the 1960s. There followed an early, highly influential randomised controlled trial of family therapy, which led to the elaboration and refinement of related interventions, especially for adolescent patients. Establishing what would be a 'healthy' weight for an individual based on follicular size on ovarian ultrasound was another clinically useful innovation.

Gerald's widely acknowledged expertise led to the establishment at the Maudsley metabolic unit of perhaps the first specialist eating disorders unit, then at the Royal Free Hospital (without any special resources on a busy general psychiatry ward) and then back at the Maudsley. He attracted numerous referrals, both national and international. The present unit honours his name.

Gerald was an enormously gifted clinician. An easy rapport was quickly established with his patients. When, as a fresh trainee, I first saw him interview a patient, I couldn't discern a 'mental state examination'. A relaxed conversation centred mostly on what was of importance for the patient. It was only after the interview, as Gerald explicated, one after another, a string of classical psychopathological features that it became obvious they had in fact been beautifully elicited in the interview. I recognised the thoroughness of the examination, its fluency and the subtlety behind its conduct. Repeatedly, many were struck by Gerald's ability to see clinical connections 
having aetiological or therapeutic implications that eluded the rest of us.

Gerald was born in 1928 in Grammont, Belgium. His father, Daniel George Russell, who was awarded a Military Cross for conspicuous gallantry in the First World War, was a British Military Attaché in the Embassy in Brussels for 13 years; his mother was Belgian. After the capitulation of Belgium in May 1940, his father succeeded in evacuating his wife, three children and relatives via Dunkirk in the face of constant bombing and machine-gun fire. An indelible impression was made on the 12-year-old boy on seeing death at close quarters. He remembered kissing the ground on reaching Dover.

Gerald's early education was in French. He finished his last school, George Watson's College in Edinburgh, in 1945 as dux and took first place in the Edinburgh Open Bursary Competition. After reading medicine at the University of Edinburgh, he served as a regimental medical officer in Germany and then, in 1954, he commenced training in neurology. Soon after, he became a Medical Research Council Clinical Research Fellow (1956-1958). John Marshall, later professor of neurology at Queen's Square, suggested that 6 months of psychiatry would stand him in good stead as a neurologist. Gerald was allowed, unusually, 6 months at the Maudsley Hospital. There he came under the powerful influence of the hugely eminent Aubrey Lewis. While still a Fellow, Gerald was allowed to switch to psychiatry, nevertheless completing his doctoral dissertation in neurology on the nervous control of the pupil. In 1959, Gerald became first assistant to Aubrey Lewis and, in 1961, he became senior lecturer at the Institute of Psychiatry and consultant at the Maudsley Hospital.

Shortly following his retirement from the Institute of Psychiatry, Gerald admitted that he missed his patients. He recommenced clinical practice, this time in the private sector, and continued into his 80 s.

Apart from his family and his rose garden, there was another great passion: art. His encyclopaedic knowledge of the subject was acquired over a lifetime of inquiry. If, in a city hosting a conference to which he had been invited, there was a gallery previously unvisited or not previously comprehensively explored, he might slip out of a session or two to visit.

Surprisingly at odds with this highly principled man were the cat-and-mouse games engaged with gallery attendants in his attempts - usually successful - to photograph paintings surreptitiously despite its prohibition by the gallery. Behind his straight-laced, though imposing demeanour there were occasional small forays against what he judged to be gratuitous authority.

In 1950 he married a fellow student in Edinburgh, Margaret Taylor, whose death in 2017 came as a harsh blow. $\mathrm{He}$ is survived by three sons whose devotion he deeply appreciated.

In a paper on Philippe Pinel, Aubrey Lewis quoted Esquirol's summation of his character. It fits Gerald Russell equally well: he was '... the La Fontaine of Medicine-"the same nicety of observation, the same quickness in seeing relationships, the same knowledge of the human heart, the same simplicity and good nature, the same disinterestedness"'. ${ }^{3}$

\section{References}

1 Russell GFM. Anorexia nervosa: its identity as an illness and its treatment. In Modern Trends in Psychological Medicine, Vol. 2 (ed J Harding Price): 131-164. Butterworths, 1970.

2 Russell GFM. Bulimia nervosa: an ominous variant of anorexia nervosa. Psychol. Med. 1979; 9: 429-48.

3 Lewis A. Philippe Pinel and The English. Proc. R. Soc. Med. 1955; 48: 581-6.

George Szmukler

doi:10.1192/bjb.2018.85

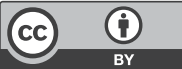

(c) The Author 2018. This is an Open Access article, distributed under the terms of the Creative Commons Attribution licence (http://creativecommons.org/ licenses/by/4.0/), which permits unrestricted re-use, distribution, and reproduction in any medium, provided the original work is properly cited.

\section{Dr Peter John Bowers, FRCPsych}

\section{Formerly Consultant Psychiatrist, Tameside and Glossop Mental Health Trust, UK}

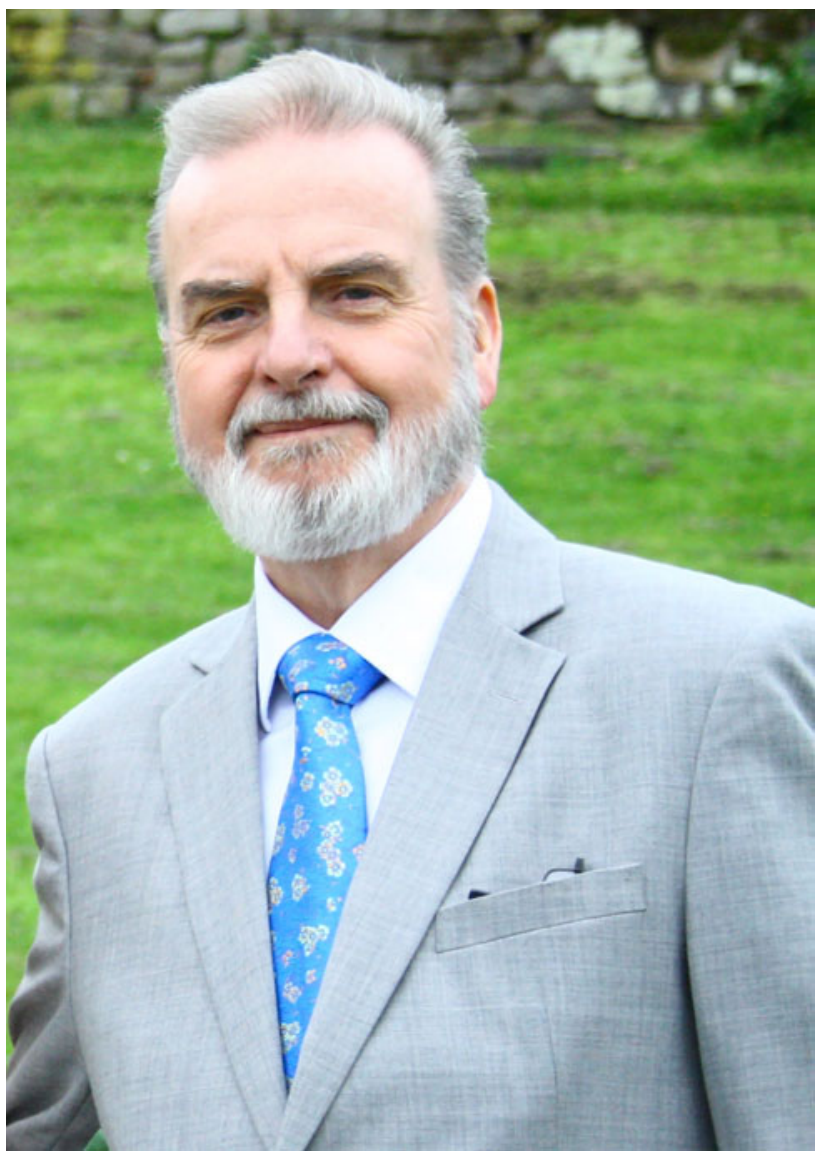

